\title{
Characterization of a hybrid flame/arc excitation source using monodisperse aerosol introduction
}

\author{
C. E. SchmidT* and R. D. SACKs† \\ Department of Chemistry, University of Michigan, Ann Arbor, Michigan 48109
}

(Received 14 September 1982)

\begin{abstract}
A hybrid flame/arc excitation source together with a monodisperse droplet generator is used to inject solute partıcles into selected regions of the arc plasma. With astigmatic image transfer and a $0.5 \mu$ s time constant detection system, individual solute vapor cloud emission profiles are detected in the arc tail flame. These emission profiles are always asymmetric with sharper leading edges. Emission profiles are presented for $\mathrm{Ca}$ at several positions in the arc tail flame. The (zinc) excitation temperature was measured at $6600 \mathrm{~K}$ in the region $1-2 \mathrm{~mm}$ above the arc conduction channel. A double aperture technique was used to estimate the arc convective velocity at about $50 \mathrm{~m} \mathrm{~s}^{-1}$. When the emission plume origin from a monodisperse droplet stream is positioned in the tail flame region, analytical line-to-background ratios typically are one-two orders of magnitude greater than when the plume origin is located below the conduction channel. Analytical curves from the tail flame region are linear over at least two-three orders of concentration, and detection limits are significantly lower than literature values for the region just under the conduction channel of an Ar-stabilized bent arc.
\end{abstract}

\section{INTRODUCTION}

THE SEARCH for a simple direct current, atmospheric pressure plasma generator compatible with nebulized solution sample introduction has produced several plasma jet and gas stabilized arc designs [1-5]. A localized conduction channel together with a hightemperature but more diffuse mantle permits spatial isolation of zones of potentially favourable analysis line-to-background intensity ratios. The effective temperatures in these regions should be sufficient to obtain complete sample atomization with minimal concomitant effects.

Despite these attractive features, solution aerosol penetration problems have frustrated the development of these systems. There is evidence that only with turbulent mixing and more complex jet configurations can this thermally induced barrier to droplet or aerosol particle penetration be overcome. The $30^{\circ}$ included angle bent arc described in 1970 by V ALENTE and SCHRENK [5] appears to have achieved satisfactory sample introduction and together with a measurement zone of low continuum background intensity in the plasma tail flame obtained detection limits in the low $\mathrm{ng} / \mathrm{ml}$ range for a number of elements. These values often still are used as standards for comparison.

Engineering complexities and operational difficulties of the Valente and Schrenk plasma jet led to the development of $90^{\circ}$ bent arc designs by ELLIOT [3] and by MerChant and VEILLON [6]. Detection limits for both jets are significantly poorer than with the Valente and Schrenk design.

The Elliott $90^{\circ}$ arc evolved to the $80^{\circ}$ symmetric bent arc which is enjoying considerable commercial success [7]. In this design, the wet aerosol is introduced in the apex region under the conduction channel. Sample penetration difficulties result in the most analytically useful region occurring just below the current channel rather than in the convective tail flame above

*Present address: Radian Corp., P.O. Box 9948, Austin, Texas 78766, U.S.A.

tAuthor to whom correspondence should be directed

[1] M. Margoshes and B. F. SCRIBNER, Spectrochim. Acta 15, 138 (1959).

[2] L. E. OWEN, Appl. Spectrosc. 15, 150 (1961).

[3] W. G. ELL1OT, Am. Lab. 3(8), 45 (1971).

[4] E. Kranz, Emissionssektroskopie, p. 160. Akademie Verlag, Berlin (1964).

[5] S. E. VALENTE and N. G. Schrenk, Appl. Spectrosc. 24, 197 (1970),

[6] P. Merchant, JR, and C. Veillon, Anal. Chem. Acta 70, 17 (1974).

[7] Spectrametrics, Inc. Model 53000 Spectrajet II Argon Plasma Jet Instruction Manual. 
the channel $[8,9]$. A saddle in the convective flow below the channel extends the residence times of aerosol droplets in this region sufficiently to provide reasonable analysis line-tobackground intensity ratios. The tail flame region might be more useful if it were more readily accessible to analyte vapor.

Coleman et al. $[10,11]$ achieved better sample penetration by adding He to the plasma support gas, reducing the interelectrode angle from $75^{\prime \prime}$ to $45^{\circ}$ and decreasing the diameter of the aerosol delivery tube. While this improved detection limits and reduced interferences, the tail flame region was still less useful than the apex region under the conduction channel.

The thermally induced barrier to sample aerosol penetration was first mentioned by KRANZ [4] and later by Fassel [12]. Holcombe [13], Skogerboe [8], and Decker [14] also have discussed it. However, no definitive description of its origin, characteristics, and possible remedies could be found.

This report describes an experimental technique developed for the study of the aerosol penetration problem and for evaluating the tail flame region with respect to analytical utulity. This technique might also prove useful in elucidating features of the arc plasma-sample interaction. However, in its present form, the system is too complex and difficult to maintain for routine analysis applications.

The technique is based on the combination of a piezoelectrically driven monodisperse droplet generator, a large volume laminar flame supported on a circular slot burner, and an Ar stabilized direct current arc discharge operated from a constant-current power supply. The droplet generator produces a stream of equal size, evenly spaced solution droplets in the 50-100 $\mu \mathrm{m}$ diameter size range. These droplets are introduced along the axis of a $\mathrm{N}_{2} \mathrm{O} / \mathrm{C}_{2} \mathrm{H}_{2}$ flame, which desolvates the droplets and accelerates them uniformly to the convective velocity of the flame gases. The combination of increased droplet or particle momentum together with precisely defined trajectory is useful for probing the arc plasma thermal barrier, and, with proper selection of arc, flame, and droplet generator parameter values, results in the detection of individual solute vapor clouds in the arc plasma tail flame. Design and performance characteristics of the system are presented here along with a discussion of the thermal barrier and a preliminary comparison of the arc tail flame and apex regions with respect to analyte line-to-background intensity ratios.

\section{Nature of the Thermal Barrier}

The thermally induced barrier to sample penetration in arc plasmas is undoubtedly of complex origin. DECKER [14] recently noted that in the apex region of a three-electrode d.c. Ar plasma source the dried analyte particles lose most of their vertical component of velocity and are deflected laterally around the plasma core by the thermal barrier. He also notes that volatilization of the sample is incomplete.

Thermal expansion of the plasma support gas or nebulization gas probably establishes a convective flow around the conduction channel. Analyte vapor trapped in this flow would bypass the hot plasma core and tail flame region. This suggests that analyte vapor cannot be transported efficiently into the high-temperature region of the arc plasma.

Because of their large surface area to mass ratio, aerosol particles are strongly affected by temperature gradients both within the particles and in the supporting medium. A temperature gradient in the gas surrounding an aerosol particle results in gas molecules hitting the particle on opposite sides with different average velocities. The resulting force is directed toward the lower temperature region. The resulting motion of the particles is known as thermophoresis. A temperature gradient in the particles results in gas molecules

[8] R. K. Skogerboe, I. T. Urasa and G. N. Coleman, Appl. Spectrosc. 30, 500 (1976).

[9] M. H. Fairless, Am. Lab. 10(3), 101 (1977).

[10] G. N. Coleman, W. P. Braun and A. M. Allen, Appl. Spectrosc. 34, 24 (1980).

[11] G. N. Coleman and A. M. Allen, Appl. Spectrosc. 36, 116 (1982).

[12] V.A. FASSEL, in Proceedings X VI Colloquium Spectroscopicum Internatıonale, Plenary Lectures and Reports, p. 63. Hilger, London (1971).

[13] J. A. Holcombe, R. H. Eklund and K. E. Grive, Anal. Chem. 50, 2097 (1978).

[14] R. J. DECKER, Spectrochim. Acta 35B, 19 (1980). 
rebounding from the hotter surface with greater average velocities. The recoil force on the particle again is directed toward lower temperature. If the temperature gradient in the particle is the result of radiation absorption on the illuminated side, the resulting particle motion is known as photophoresis. For particles in the $\mu \mathrm{m}$ size range, these forces can be remarkably large. FucHs [15] reviewed these radiometric forces.

For the case where the particle radius $r$ is less than the molecular mean free path $\lambda$ in the surrounding gas, WaLdManN [16] derived an expression for the thermophoretic force $F$,

$$
F_{t}=-\frac{4 r^{2} P \lambda G_{g}}{T}
$$

where $P$ is pressure, $G_{g}$ the temperature gradient in the gas, and $T$ the temperature. While a detailed evaluation of $F_{t}$ for the bent arc system is not practical since gas kinetic temperature profiles are unavailable, an approximate evaluation is revealing. Using the line reversal temperature profiles of SKOGERBOE et al. [8] the region between 1 and $2 \mathrm{~mm}$ below the conduction channel of the Ar-stabilized bent arc is characterized by a vertical temperature gradient of $\sim 6000 \mathrm{~K} \mathrm{~cm}^{-1}$ and a temperature of $\sim 2000 \mathrm{~K}$. The mean free path is about $0.5 \mu \mathrm{m}$ at this temperature [17]. A $5 \mu \mathrm{m}$ solution droplet of $1000 \mu \mathrm{g} \mathrm{ml}^{-1} \mathrm{NaCl}$ from a conventional pneumatic nebulizer after desolvation would form a $0.19 \mu \mathrm{m}$ radius crystal. From Eqn 1, the thermophoretic force is found to be about $2.1 \times 10^{-8}$ dynes and produces an acceleration of $3.4 \times 10^{5} \mathrm{~cm} \mathrm{~s}^{-2}$. If the particle has an initial velocity in the direction of the temperature gradient of $100 \mathrm{~cm} \mathrm{~s}^{-1}$ and if only inertial forces are considered, the particle direction would be reversed in only $0.3 \mathrm{~ms}$ and after penetrating $0.15 \mathrm{~mm}$ into the temperature gradient.

While these calculations are somewhat naive, they do indicate that $F$, may be sufficiently large to prevent sample penetration under analytically realistic conditions. Since inertial force increases linearly with particle volume while $F$, increases linearly with surface area, for a given injection velocity, large particles more easily penetrate the thermal barrier. This would result in a general increase in analytical line intensities with increasing total salt content of the sample. Such increases have been observed $[14,18,19]$. It should be noted that a relatively small increase in particle penetration could produce a significant enhancement. From the electronic excitation temperature profiles of SKOGERBOE $e t$ al. [8] and neglecting changes in partition function over a $100 \mathrm{~K}$ range, a penetration increase of $0.1 \mathrm{~mm}$ would result in a more than $20 \%$ intensity increase for a transition with a $3.5 \mathrm{eV}$ upper state excitation energy. Improved atomization at the higher temperature could amplify this process.

Again for the case where the particle radius is less than the mean free path, the photophoretic force $F_{p}$ is given by [20]

$$
F_{p}=-\frac{\pi r^{3} P G_{p}}{3 T}
$$

where $G_{p}$ is the temperature gradient in the particle. The value of $G_{p}$ is difficult to evaluate since it depends on a number of properties of both the analyte particle and the radiation source. However, because of the large radiant flux from the arc conduction channel, $F_{p}$ may be quite large, particularly for strongly absorbing solutes of low thermal conductivity. Reverse photophoresis (motion of particle toward higher temperature) has been observed for some transparent materials where internal reflections result in greater heating on the side of the particle further from the radiation source [21].

Since both inertial and photophoretic forces increase linearly with particle volume, particle penetration with respect to photophoresis only should not be effected in a general way by total salt content as in the case of thermophoresis. However, chemically specific concomitant

[15] N. A. Fuchs, The Mechanics of Aerosols. Pergamon Press, New York (1964).

[16] L. WaldmanN, Z. Naturforsch 14a, 589 (1959).

[17] P. W. J. M. Boumans, Theory of Spectrochemical Excitation, Plenum Press, New York (1966).

[18] G. W. Johnson, H. E. Taylor and K. K. Skogerboe, Appl. Spectrosc. 34, 19 (1980).

[19] D. Eastwood, M. S. Hendrick and G. Sogliero, Spectrochim. Actc 35B, 421 (1980).

[20] S. Rubinowitz, Ann. Physik 62, 695 (1920).

[21] F. Deguillon, C. R. Acad. Sci. Paris 231, 274 (1950). 
effects should occur because of the effects of concomitant species on the absorption spectrum and thermal conductivity of the solute particle. SCHADT and CADLE [22] observed that the radiometric force on Fe particles in a thermal precipitator is only about $20{ }_{\circ}^{\circ}$ as large as on $\mathrm{NaCl}$ particles. This was attributed to the greater thermal conductivity of $\mathrm{Fe}$.

While a number of experimental studies of radiometric forces on aerosols have been documented [15], generally they involved much lower temperatures nd smaller temperature gradients than in the arc plasma. From a qualitative viewpoint, radiometric forces no doubt are present and may be sufficiently large to prevent aerosol particles from entering the highest temperature regions of the arc plasma. It should be noted that because of the direction of convective flow, the apex region just under the conduction channel is the least satisfactory with respect to aerosol penetration. That is, temperature gradients and thus the radiometric forces are largest in this region.

\section{EXPERIMENTAL}

A block diagram showing the important components of the hybrid droplet generator/flame/arc system is shown in Fig. 1. The entire system is mounted on a stage which allows vertical positioning of the burner port relative to the optical axis without changing the relative positions of the flame, are and droplet generator. A second, motor-driven stage is used for horizontal scans of the entire apparatus normal to the optical axis. The monodisperse droplet generator is mounted below the $\mathrm{N}_{2} \mathrm{O} / \mathrm{C}_{2} \mathrm{H}_{2}$ circular slot burner and introduces a droplet stream axially into the cylindrical flame. Vertical adjustments of the burner and the arc electrode holders provide for independent control of the droplet generator-to-burner port and the burner port-to-arc plasma distances.

\subsection{Droplet generator}

The droplet generator, shown in Fig. 2, is a significantly modified version of one described by Berglund [23] and by JosH and SACKs [24]. A ring-shaped piezoelectric bimorph transducer, $1.27 \mathrm{~cm}$ i.d., $2.54 \mathrm{~cm}$ o.d., $2.5 \mathrm{~mm}$ thick (Channel Industries) is used to disturb a liquid jet stream which is produced by forcing a solution through a pinhole orifice. If this mechanical disturbance is periodic with constant frequency, the liquid jet may break up into uniform, equally spaced droplets. The formation of monodisperse droplets is dependent on the transducer excitation frequency, pinhole diameter and solution flow rate.

The surfaces of the transducer are tinned, and the ring is cemented with conductive epoxy to a

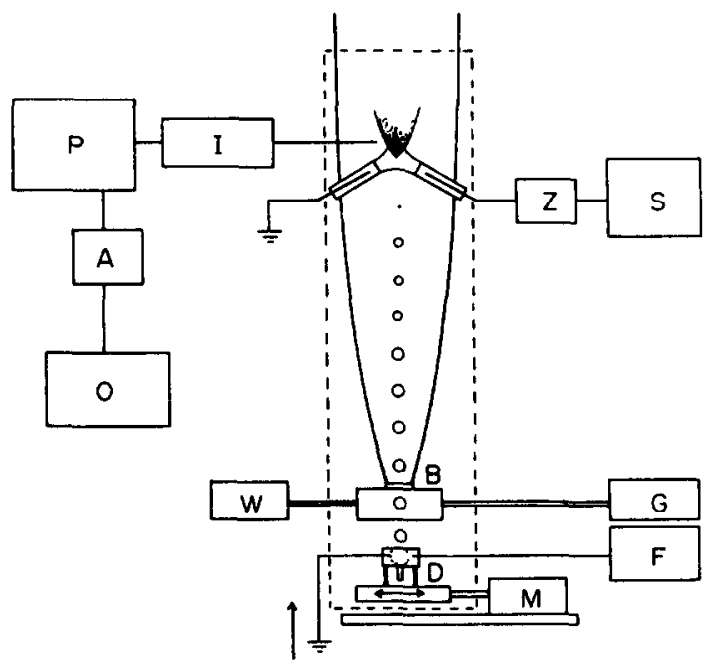

Fig. 1. Block diagram of droplet generator/flame/arc system. M, motor driven stage; F, function generator; S, constant current supply; $Z$, ballast resistor and surge filter; $D$, droplet generator. $B$, circular slot burner; $G$, gas supply and regulators; W, cooling water supply: 1 , image transfer system; P, monochromator; A, photomultiplier tube; O, digital storage oscilloscope.

[22] C. Schadt and R. Cadle, J. Coll. Sci. 12, 356 (1957).

[23] R. N. Berglund, Ph.D. dissertation, University of Minnesota, 1972.

[24] B. M. JoshI and R. D. SACKs, Anal. Chem. 51, 1781 (1979). 


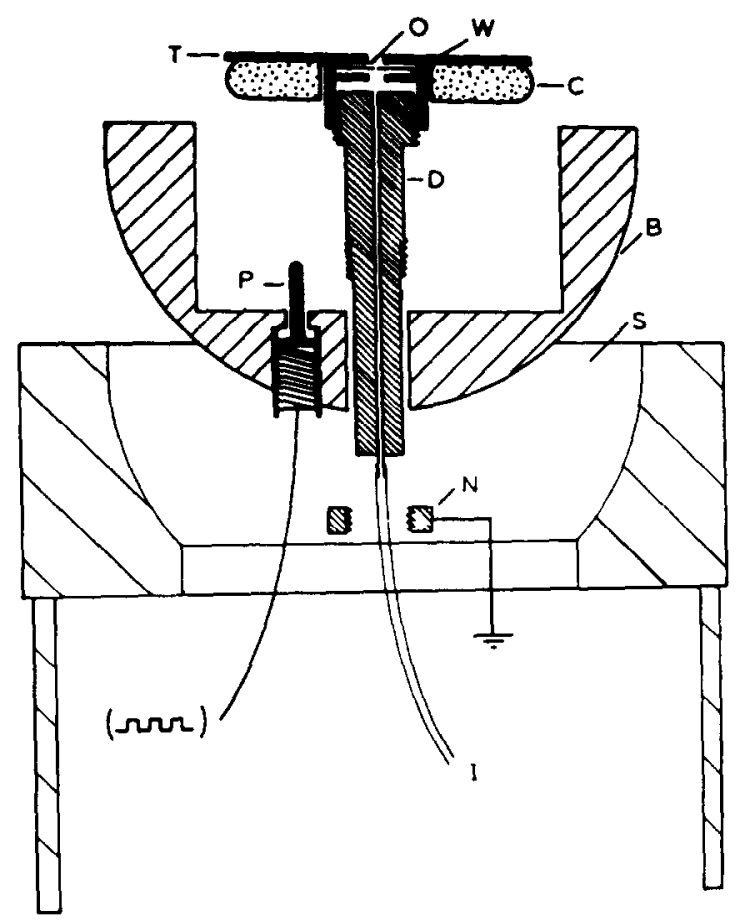

Fig. 2. Exploded view of piezoelectric droplet generator. $C$, piezoelectric bimorph transducer; $O$, pinhole orifice; $T$, stainless steel head; $W$, nylon washer; $D$, sample delivery post; $P$, spring-loaded contact: B, brass hemisphere; S. plastic socket: $N$. retainer nut and ground contact: 1 . sample inlet.

threaded stainless steel head which holds the pinhole in contact with the transducer surface and the sample delivery post. The upper surface of the transducer is grounded, and a $5 \mathrm{~V}$ peak-to-peak square wave from a $0-5 \mathrm{MHz}$ Wavetec signal generator is delivered to the lower surface by a spring-loaded contact.

The $9.5 \mathrm{~mm}$ diameter, $0.30 \mathrm{~mm}$ thick stainless steel disk containing the pinhole $(15-30 \mu \mathrm{m}$, Optimation Corp.) is sealed in the transducer head with a nylon washer. Sample solution is delivered at a constant flow rate by a simple pressure pump operated at $18-20$ psi gauge pressure. Solution flow rate is calculated by measuring the time required for an air bubble injected in the delivery tube to traverse a measured segment of the tubing. The droplet size is computed from the solution flow rate and the excitation frequency.

The assembled transducer unit is mounted in a $1.9 \mathrm{~cm}$ radius hollow brass hemisphere so that the pinhole orifice is located at the sphere center. The hemisphere is retained in a socket-shaped plastic stand which is mounted under the circular slot burner. This ball-socket design provides continuously variable control of the droplet stream trajectory in the flame. During operation, the sample delivery post is used as a handle and the generator adjusted to provide the desired trajectory.

\subsection{Circular slot burner}

A detailed description of the burner is given by JosH and $S_{A C K S}$ [24]. The $\mathrm{N}_{2} \mathrm{O} / \mathrm{C}_{2} \mathrm{H}_{2}$ gas mixture is introduced into the water-cooled inner body of the burner and exits from the $9.2 \mathrm{~mm}$ i.d., $9.5 \mathrm{~mm}$ o.d. circular slot. The droplet stream is introduced through a $6.3 \mathrm{~mm}$ diameter hole in the center of the burner head. The laminar flame is operated at an oxidant-to-fuel ratio of about 2.0.

\subsection{Direct current arc plasma generator}

A gas-stabilized, bent arc configuration [3] was chosen for its simplicity, ease of operation and commercial availability. The $0.1 \mathrm{~cm}$ diameter $\mathrm{Zr}$ doped $\mathrm{W}$ electrodes, the inner electrode holders and the $3.2 \mathrm{~mm}$ i.d. ceramic sleeves were obtained from Spectrametrics, Inc. However, the water-cooled outer holders were redesigned to provide adjustment of the bent-arc angle and to move water cooling lines and other combustible parts away from the $\mathrm{N}_{2} \mathrm{O} / \mathrm{C}_{2} \mathrm{H}_{2}$ flame.

The arc was operated from a 0-30 A constant current power supply (Electronics Measurements, Inc.). This supply has an open-cricuit output voitage of $180 \mathrm{~V}$ and current regulation of at least $\pm 1 \%$. A $3.5 \Omega$ power resistor in series with the arc provides ballast. The parallel combination of a $0.5 \mathrm{H}$ inductor and a $32.5 \Omega$ resistor is used as a series surge filter. 


\subsection{Radiation detection system}

A pair of $30 \mathrm{~cm}$ focal length $f / 6$ spherical mirrors is used to image the plasma onto the entrance slit of a 0.75-m Czerny-Turner spectrometer (Jarrell-Ash Model 78-462), which has a reciprocal linear dispersion of $1.1 \mathrm{~nm} \mathrm{~mm}^{-1}$. Astigmatic imaging, as described by SALMON and HoLcombe [25], is used to improve spacial resolution of the plasma and to increase radiation throughput to the monochromator. The mirrors are positioned to produce about a $3.2 \mathrm{~cm}$ separation of the horizontal tangential and the vertical sagittal foci. A $0.5 \mathrm{~mm}$ wide horizontal slit is positioned at the tangential image plane. This provides for vertical spatial resolution of the plasma. The sagittal image is focused onto the $100 \mu \mathrm{m}$ wide entrance slit of the monochromator. Unit magnification was used. A peep-sight cathetometer aligned on the optical axis was used to position the desired region of the plasma on the optical axis. Positional reproducibility was about $\pm 0.25 \mathrm{~mm}$.

Radiation was detected by a $1 \mathrm{P} 28$ photomultiplier tube biased at $1.0 \mathrm{kV}$. Transient radiation profiles of individual solute vapor clouds at selected regions of the arc tail flame were recorded on a Nicolet 1090A digital storage oscilloscope operated at a $2.0 \mathrm{MHz}$ sampling rate. A $100 \Omega$ load resistor was used to give a measured circuit time constant $\sim 0.5 \mu \mathrm{s}$. Spatial profiles across the arc tail flame were obtained by translating the entire apparatus normal to both the flame axis and the optical axis at a rate of $2.1 \mathrm{~mm} \mathrm{~s}^{-1}$. The region of interest is about $8 \mathrm{~mm}$ wide and is scanned in $\sim 4 \mathrm{~s}$. This represents about $3 \times 10^{4}$ individual solute droplets. Here, a $10 \mathrm{k} \Omega$ load in parallel with a $1.0 \mu \mathrm{F}$ capacitor was used. This gives a circuit time constant of $0.01 \mathrm{~s}$. The voltage drop across this load was recorded on a strip chart recorder or digital oscilloscope without further amplification or processing. For analytical curves and detection limits, the radiation signal from a region along the tail-flame axis was recorded for about $30 \mathrm{~s}$.

\subsection{Temperature and convective velocity measurements}

The two-line, intensity ratio method was used to measure the arc tail-flame electronic excitation temperature in the region from 1.0 to $2.0 \mathrm{~mm}$ above the current channel. Zinc was chosen as a thermometric species because it produced a stable emission plume in the arc tail flame, and two suitable neutral-atom emission lines were found in a wavelength region of very low flame emission. Boumans [17] discussed the suitability of $\mathrm{Zn}$ as a thermometric species. A $1000 \mu \mathrm{g} \mathrm{ml}^{-1}$ solution of $\mathrm{ZnCl}_{2}$ was introduced into the flame/arc system as a monodisperse droplet stream, and peak intensities of the 307.21 and $307.59 \mathrm{~nm}$ lines from wavelength scans across these lines were used. The excitation potentials for these transitions are 8.1 and $4.0 \mathrm{eV}$, respectively.

Convective velocity in the flame was measured at several distances from the burner port by photographing through a calibrated shutter the luminous tracks produced from Fe powder introduced at the base of the flame. The shutter speed was calibrated with an EG \& G TD-110 photodiode in place of the photographic emulsion. The output voltage pulse across a $1.0 \mathrm{k} \Omega$ load was recorded on the digital storage oscilloscope. This method for convective velocity measurement was discussed by Borgers et al. [26].

Convective velocity in the arc was measured using a method similar to one described by Boss and HIEFTJE [27]. The single horizontal slit was replaced by a mask containing two $0.83 \mathrm{~mm}$ wide apertures spaced $2.9 \mathrm{~mm}$ between their centers. This produced double peaks on single vapor cloud temporal profiles recorded on the digital oscilloscope. Convective velocity is estimated from the time between the two peaks. The $0.5 \mu \mathrm{s}$ time constant measurement circuit was used.

\subsection{Reagents}

Deionized, distilled water was used in all sample solutions. All solutions were filtered through $0.45 \mu \mathrm{m}$ pore diameter membrane filters. Stock solutions $\left(1000 \mu \mathrm{g} \mathrm{ml}^{-1}\right)$ were prepared from reagent grade salts. Volumetric dilutions were made on a daily basis as needed.

\section{Results AND Discussion}

Figure 3 shows sketches of the arc plasma when operated in a conventional mode with an $80^{\circ}$ included interelectrode angle (Fig. 3a) and in the $\mathrm{N}_{2} \mathrm{O} / \mathrm{C}_{2} \mathrm{H}_{2}$ flamc, where convective flow in the flame distorts the arc, and a $120^{\circ}$ included angle was found to be more stable (Fig. 3b). However, in the apex region below the arc channel, the convective distortion results in an effective included plasma angle of about $40^{\circ}$. COLEMAN et al. [10] recently demonstrated a significant increase in signal-to-noise ratio for neutral-atom $\mathrm{Cr}$ radiation when the arc angle 
(a)

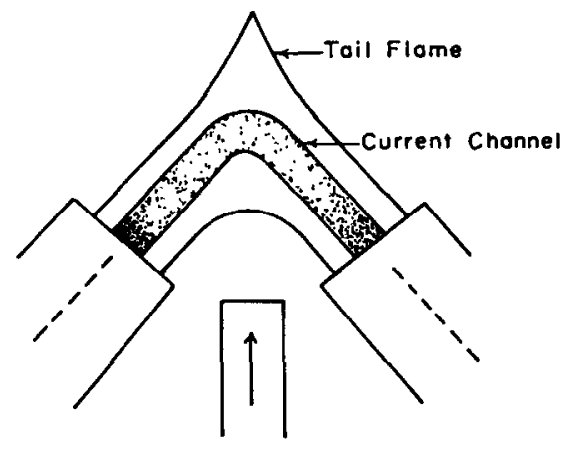

(b)

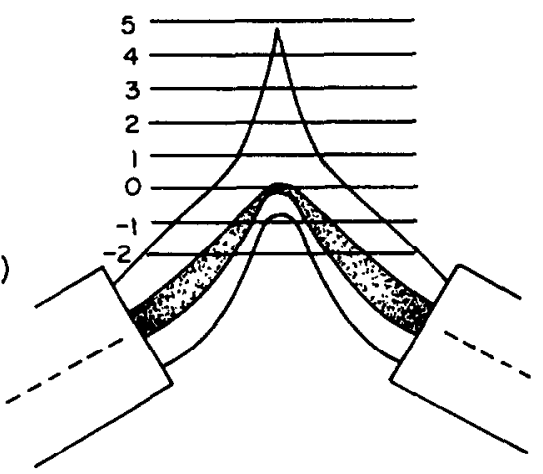

Fig. 3. Sketches of the Ar-stabilized bent arc plasma operating (a) in the conventional mode with an $80^{\circ}$ interelectrode angle and (b) in the $\mathrm{N}_{2} \mathrm{O} / \mathrm{C}_{2} \mathrm{H}_{2}$ flame with a $120^{\circ}$ interelectrode angle.

is reduced from $75^{\circ}$ to $45^{\circ}$. They attribute this to greater aerosol entrainment and penetration in the $45^{\circ}$ plasma.

The apparent boundaries of both the current channel and the luminous mantle vary considerably with Ar cooling gas flow rate, and the sketches in Fig. 3 should be loosely interpreted. In general, however, the current channel appears narrower when the arc is operated in the $\mathrm{N}_{2} \mathrm{O} / \mathrm{C}_{2} \mathrm{H}_{2}$ flame.

Figure 3 also shows the coordinate system used in subsequent discussion. The bottom of the current channel in the region of the arc apex is assigned a vertical coordinate of 0.0 . Regions below the arc apex are assigned negative coordinate values; while positive values are assigned to regions in the plasma above the apex of the inverted $\mathrm{Y}$.

\subsection{Operation of the hybrid system}

Table 1 lists the parameter values for the droplet generator, flame and arc used for most of the studies reported here. The choice of parameter values for the generator and the flame are

Table 1. Operating parameters of the hybrid system

\begin{tabular}{ll}
\hline $\begin{array}{l}\text { Droplet generator } \\
\text { Pressure }\end{array}$ & $20 \mathrm{psi}$ \\
Solution flow rate & $0.16-0.30 \mathrm{ml} \mathrm{min}^{-1}$ \\
Excitation frequency & $0.5-14 \mathrm{kHz}$ \\
Pinhole diameter & $20 \mu \mathrm{m}$ \\
Droplet diameter & $60-100 \mu \mathrm{m}$ \\
Flame & \\
$\mathrm{N}_{2} \mathrm{O}$ flow rate & $6.71 \mathrm{~min}^{-1}$ \\
$\mathrm{C}_{2} \mathrm{H}_{2}$ flow rate & $3.31 \mathrm{~min}^{-1}$ \\
Arc & \\
Interelectrode angle & $120^{\circ}$ \\
Gap length & $10 \mathrm{~mm}^{-1}$ \\
Ar flow rate & $2.81 \mathrm{~min}^{-1}$ \\
Current & $7.0 \mathrm{~A}$ \\
Voltage & $40-60 \mathrm{~V}$ \\
\hline
\end{tabular}


discussed in Ref. [24]. A parametric study of the arc revealed that Ar cooling gas flow rates less than about $1.31 \mathrm{~min}^{-1}$ result in rapid electrode deterioration, while values greater than about $4.61 \mathrm{~min}^{-1}$ result in severe arc instability. In the flame, however, values greater than about $2.4 \mathrm{l} \mathrm{min}^{-1}$ result in excessive perturbation of the convective flow in the flame. This rather low flow rate also results in a larger, more diffuse plasma which is more easily penetrated by the solute particle stream.

For almost any combination of arc gap length, current and cooling gas flow rate the arc was considerably more stable in the $\mathrm{N}_{2} \mathrm{O} / \mathrm{C}_{2} \mathrm{H}_{2}$ flame relative to conventional operation. This may result from the electrical conductivity of the flame. LesNikova and KHURIN $[28,29]$ reported increased stability of a carbon arc when operated in an air $/ \mathrm{C}_{2} \mathrm{H}_{2}$ flame. This greater stability permitted the use of a $1.0 \mathrm{~cm}$ gap length which simplified operation of the hybrid system.

Attempts at introducing the monodisperse droplet stream directly into the arc plasma failed completely. While large droplets with the proper trajectory could be forced through the plasma, complete desolvation did not occur. When droplets penetrated the plasma, an audible disturbance occurred. This probably was caused by turbulence from the rapid vaporization of the water.

The monodisperse droplets produced by the piezoelectric generator typically are about an order of magnitude greater in diameter than droplets produced by spray-chamber, pneumtic nebulizers [30]. The resulting solute particles moving at the convective velocity of the flame have several thousand times the momentum of the particles used in conventional arc operation. This, coupled with smaller temperature gradients in the hybrid system, permits the direct injection of solute particles into the tail flame region.

When uniform droplets are introduced along a well defined trajectory in the flame, analyte emission begins at nearly the same point in the flame or arc plasma for each resulting solute particle. Because of the relatively high droplet introduction rate, $\sim 10 \mathrm{kHz}$, the locus of outer boundaries from the expanding analyte vapor clouds produces the appearance of a steadystate, comet-shaped emission plume with a head located at a fixed position in the flame or arc. This is discussed in more detail in Ref. [31]. The small size of the arc tail flame region together with extreme temperature gradients requires that the origin point of the emission plume be positionally stable if the monodisperse droplet technique is to be useful for probing the arc tail flame. Under favourable conditions, the emission plume origin is stable to within $\pm 0.25 \mathrm{~mm}$.

The combination of Ar cooling gas flow and the thermally induced barrier to aerosol penetration results in divergence of aerosol droplets or particles directed toward the arc apex. Thus, a small trajectory error in the droplet stream below the arc results in the deflection of the stream away from the hottest region of the arc plasma. This lensing effect is much more easily seen with the monodisperse aerosol stream than with conventional pneumatic nebulization and may be an important reason why the apex below the arc rather than the tail flame region has proven more useful for anlytical applications.

The combination of emission plume instability and convective turbulence in the region of extreme thermal gradients near the arc conduction channel results in a rather noisy signal. This problem is exacerbated by the very small measurement circuit time constant needed for recording individual vapor cioud profiles.

\subsection{Single particle emission profiles}

Temporal radiation profiles were observed with the origin of the emission plume located about $1 \mathrm{~mm}$ above the arc conduction channel. The optical axis was located about $1 \mathrm{~mm}$ above the plume origin. Figure 4 shows the relative intensity profiles (line plus background) of two sequential $8.6 \mu$ m diameter $\mathrm{NiCl}_{2}$ particles from a $1000 \mu \mathrm{g} \mathrm{ml}^{-1} \mathrm{Ni}$ solution. The time span between the peaks was measured at $897 \mu \mathrm{s}$. This corresponds to a droplet production frequency of $1115 \mathrm{~Hz}$. The transducer excitation frequency was measured at $1111 \mathrm{~Hz}$. 


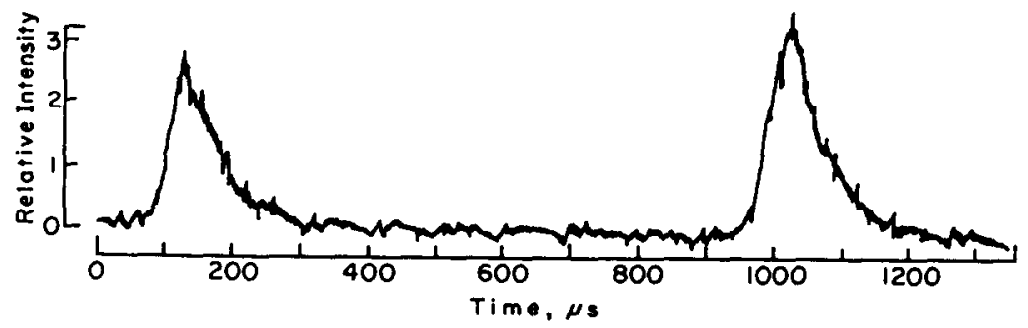

Fig. 4. Intensity-time profiles from two sequential $8.6 \mu \mathrm{m}$ diameter $\mathrm{NiCl}_{2}$ particles. The vapor plume origin was located $\sim 1 \mathrm{~mm}$ above the arc channel, and the optical axis was located $\sim 1 \mathrm{~mm}$ above the plume origin.

Because of the rather limited size of the arc tail flame, it was necessary to make all measurements within about $5 \mathrm{~mm}$ of the conduction channel. In addition, it was necessary to position the vapor plume origin in the tail flame region. If the plume origin is located under the arc channel, the analyte vapor is swept around the channel and bypasses the tail flame. Thus, all measurements presented here were made within $4.0 \mathrm{~mm}$ of the vapor plume origin. The position of the vapor plume origin has a vertical uncertainty of about $\pm 0.5 \mathrm{~mm}$ in the tail flame. These features combine to produce a significant fluctuation in the peak intensity values in a sequence of single particle emission profiles.

The emission profiles in Fig. 4 and all single particle profiles observed in this work are significantly asymmetric with relatively sharper leading edges. For the optical system used here, an asymmetric profile is expected if the analyte vapor cloud undergoes significant diffusive expansion during the time required for it to pass through the observation zone. If the solute particle vaporizes very quickly and expands by isotropic diffusion, the atomic number density $n$ as a function of time and position is given by [32]

$$
n=\frac{N}{(4 \pi D t)^{3 / 2}} \exp \left[\frac{-\left(X^{2}+Y^{2}+Z^{2}\right)}{4 D t}\right]
$$

where $N$ is the total number of analyte atoms in the vapor cloud, and $D$ is the diffusion coefficient for the atomic vapor. This is for a coordinate system located at the vapor cloud center. Equation (3) should be cautiously interpreted since particle vaporization is not instantaneous, and because of the large temperature gradients in arc plasma, the diffusion coefficient is not really single valued throughout the expanding vapor cloud.

For the laboratory fixed coordinate system with $Z$ along the flame axis and $Y$ along the optical axis, the $Z$ coordinate relative to the point of particle vaporization (vapor plume origin) can be expressed as

$$
Z=v\left(t-\frac{l}{v}\right)
$$

where $v$ is the convective velocity in the arc tail flame, and $l$ is the vertical distance from the point of particle vaporization to the optical axis. Combining these equations and noting that $X=0$ for the optical system employed here, an expression can be obtained for the time dependent detector response (emission profile) $R(t)$.

$$
K(t)=C \int_{0}^{\infty} \frac{N}{(4 \pi D t)^{3 / 2}} \exp \left\{\frac{-\left[Y^{2}+v^{2}(t-[l / v])^{2}\right]}{4 D t}\right\} \mathrm{d} Y .
$$

Here $C$ is an instrumental constant containing the optical window dimensions as well as aperture and detector sensitivity factors.

Integration of Eqn (5) gives the form of the emission profile.

$$
R(t)=\frac{C N}{4 \pi D t} \exp \left[\frac{-v^{2}(t-[l / v])^{2}}{4 D t}\right]
$$


The effects of diffusion coefficient on the emission profile are illustrated in Fig. 5 where plots of $R(t)$ vs $t$ are presented for four relative values of $D$. The curves are normalized to unit detector response when the vapor cloud center crosses the optical axis $(t=l / v)$. This is indicated by the broken vertical line at $t=0$ in the laboratory fixed coordinate system. Diffusion coefficients for the four curves have relative values of $1,2,4$ and 8 . In addition to an overall increase in profile breadth, an increase in diffusion coefficient results in increased asymmetry and a shift in the profile peak to earlier time relative to the center of the vapor cloud. The shape of the leading edge of the emission profiles in Fig. 5 is relatively insensitive to the magnitude of the diffusion coefficient. The trailing edge, however, is strongly affected, and very long tails are observed for large values of $D$.

These features are further illustrated in Fig. 6 which shows single particle emission profiles for $\mathrm{Ca}$ from $0.40 \mu \mathrm{m}$ diameter $\mathrm{CaCl}_{2}$ particles. The vapor plume origin was located about $1.0 \mathrm{~mm}$ above the conduction channel, and profiles were recorded at $1.0,2.0,3.0$ and $4.0 \mathrm{~mm}$ above the plume origin. The asymmetric peak shape with significant tailing is observed in all cases. The greatest peak intensity is observed $2.0 \mathrm{~mm}$ above the vapor plume origin. From Eqn (6), greater peak intensity should occur $1.0 \mathrm{~mm}$ above the plume origin. This suggests

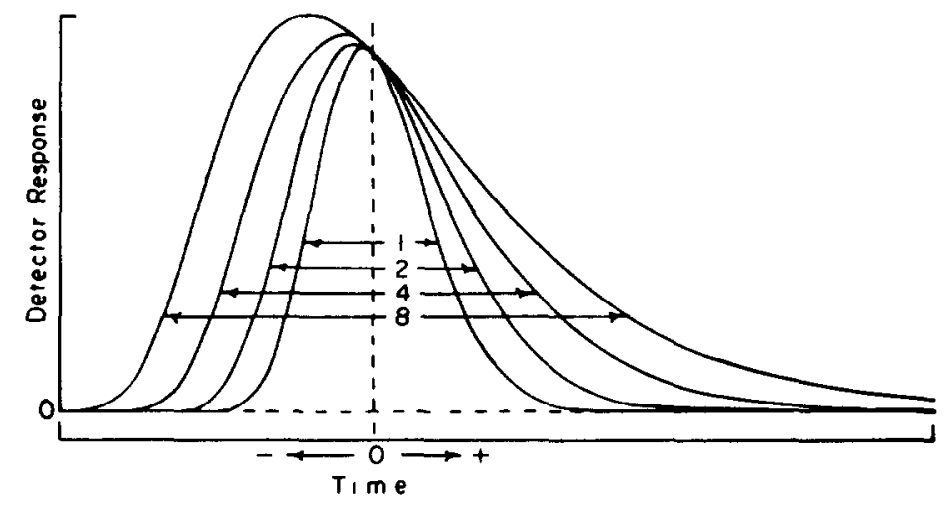

Fig. 5. Plots of $R(t)$ vs $t$ from Eqn (6). The numbers shown on the curves represent relative values of diffusion coefficient. The vertical line at $t=0$ corresponds to the vapor cloud center crossing the optical axis.

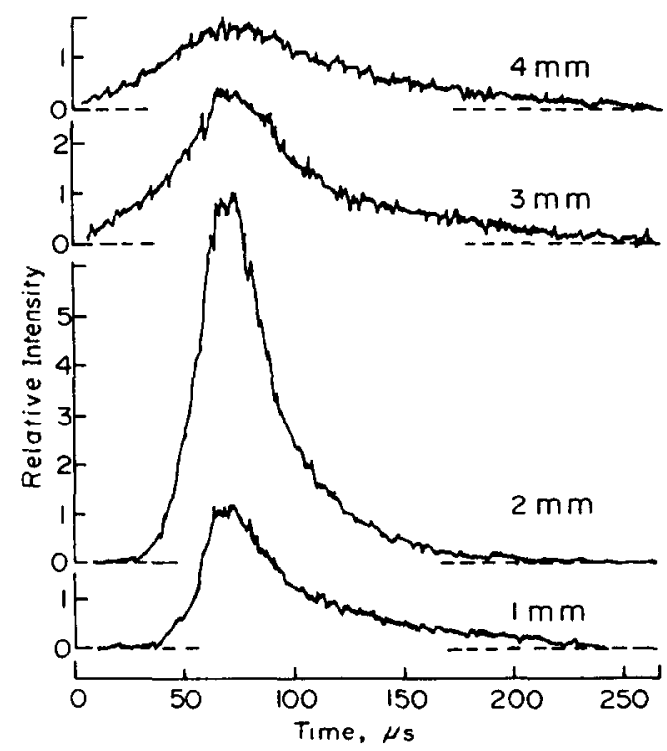

Fig. 6. Emission profiles for the $\mathrm{Ca}(1) 422.7 \mathrm{~nm}$ line from $0.40 \mu \mathrm{m}$ diameter $\mathrm{CaCl}_{2}$ particles at four different heights above the vapor plume origin. The plume origin was located $\sim 1 \mathrm{~mm}$ above the arc current channel. 
that particle vaporization is less complete for the $1.0 \mathrm{~mm}$ trace. BASTIAANS and HIEFTJE [33] studied particle vaporization at fiame temperatures and showed that more than a millisecond may be required for complete vaporization of particles of the size range used here. While vaporization at arc temperatures may be much more rapid, the assumption of rapid, complete vaporization is unrealistic when measurements are made very near the plume origin. Qualitatively similar emission profiles were obtained for $\mathrm{Ni}$ radiation from $6.4 . \mu \mathrm{m}$ diameter $\mathrm{NiCl}_{2}$ particles.

The shapes of thesc emission profiles reflect not only differences in analyte vapor transport but also differences in the temperature dependence of relative excited state populations and the concentration dependence of ionization. It should be noted that the small size of the arc plasma results in severe temperature gradients. Thus, the four observation zones used to record the emission profiles in Fig. 6 are characterized by significantly different temperatures.

\subsection{Convective velocity and temperature measurements}

The convective velocity of the flame was measured at a number of vertical positions in the flame and average values computed for four $6-\mathrm{cm}$ long zones centered at 3.0, 9.0, 15.0 and $21.0 \mathrm{~cm}$ above the burner port. Values of $760,670,610$ and $550 \mathrm{~cm} \mathrm{~s}^{-1}$ were obtained in these zones, respectively. For most measurements, the arc plasma was located $\sim 15 \mathrm{~cm}$ above the burner port. The significant decrease in convective velocity with increasing distance from the burner port results in part from the flow perturbation caused by the presence of the arc electrodes and the Ar cooling gas flow in the flame.

Very little information is available regarding the convective flow in arcs of analytical interest. The few reported studies usually involved the free burning vertical carbon are in air $[34,35]$. Further, these studies generally involved measurements in the arc conduction channel. This is of relatively less interest for gas stabilized arcs used with nebulized solution samples where the analyte may be effectively excluded from the arc channel region.

Initial attempts at photographing Fe particle tracks in the arc tail flame were unsuccessful because of the small size of the tail flame region and rejection of the particles by the arc plasma. Emission profiles from $36 \mathrm{NiCl}_{2}$ particles were obtained with the double aperture technique monitoring the $\mathrm{Ni}$ (I) $341.4 \mathrm{~nm}$ line. The lower aperture was located about $1.5 \mathrm{~mm}$ above the current channel. The time span between the double peaks was measured, and an average convective velocity of $\sim 50 \mathrm{~m} \mathrm{~s}^{-1}$ was obtained. Convective turbulence near the arc current channel resulted in considerable variation for these 36 measurements, and a relative standard deviation of $\pm 30 \%$ was obtained. Possible changes in the location of the emission profile maximum relative to the vapor cloud center as the observation zone is changed makes these measurements suspect without further characterization of the tail flame region.

Reliable computations of arc excitation temperature require spatially resolved intensity measurements. This is difficult for the bent arc configuration since there is no symmetry axis to facilitate deconvolution of spacially resolved intensities. Temperature measurements obtained without deconvolution represent weighted averages along the optical axis and should tend to underestimate the maximum plasma temperature. In this respect, the monodisperse aerosol technique is well suited for plasma temperature measurements since the region of analyte emission can be sufficiently localized in the plasma that it occurs in a relatively isothermal region. This largely obviates the need for deconvolution and should obtain more reliable values for excitation temperature in specified regions of the plasma.

Ten measurements of the $307.6 \mathrm{~nm} / 307.2 \mathrm{~nm} \mathrm{Zn(I)} \mathrm{intensity} \mathrm{ratio} \mathrm{from} \mathrm{wavelength} \mathrm{scans}$ resulted in a mean temperature of $6600 \mathrm{~K}$ in the region 1.0 to $2.0 \mathrm{~mm}$ above the arc current channel. Positional instability in the $\mathrm{Zn}$ vapor plume origin resulted in considerable variation in the intensity ratio, and the relative standard deviation in temperature is $\pm 6.0 \%$.

Table 2 presents temperature data for several arc designs. Extreme thermal gradients in the arc make it difficult to make meaningful temperature comparisons, and the values in Table 2 are estimates for the region $\sim 1 \mathrm{~mm}$ above the conduction channel. The temperature 
Table 2. Comparison of arc temperature measurements

\begin{tabular}{lcl}
\hline Arc Type & Temperature $(\mathrm{K})$ & \multicolumn{1}{c}{ Method } \\
\hline Hybrid bent arc & 6600 & Line ratio $(\mathrm{Zn})$ \\
Bent arc $^{\mathrm{a}}$ & 6100 & Line ratio $(\mathrm{T}, \mathrm{V}, \mathrm{Cd}, \mathrm{Fe})$ \\
Bent arc $^{\mathrm{b}}$ & 5600 & Line ratio (Ar) \\
Plasma jet $^{\mathrm{c}}$ & 5700 & Line ratio (Ar) \\
Plasma jet $^{\mathrm{d}}$ & 6500 & Line ratio (W, Ba, Ca, Co, Cu, \\
& & Fe, Na) \\
3-electrode bent arc & 6400 & Line ratio $(\mathrm{Zn})$ \\
\hline
\end{tabular}

a See Ref. [3].

bSee Ref. [8].

c See Ref. [6].

dSee Ref. [4].

Eee Ref. [14]

reported here is in reasonable agreement with the values of ELLIOT [3], KRANZ [4], and DECKER [14].

\subsection{Line-to-background ratios in the apex and tail flame regions}

No direct comparison of the apex and tail flame regions regarding analysis line-tobackground intensity ratios previously has been attempted since the tail flame region may not be accessible to the polydisperse aerosols produced by pneumatic or ultrasonic nebulization.

Figure 7 shows plots of the background corrected Ni(I) $341.4 \mathrm{~nm}$ line intensity (solid line) and continuum backgound intensity (broken line) as functions of vertical position in the arc with the conduction channel located at $0 \mathrm{~mm}$. A $100 \mu \mathrm{g} \mathrm{ml}^{-1} \mathrm{Ni}$ solution as $\mathrm{NiCl}_{2}$ was introduced along the flame axis as a monodisperse stream of $80 \mu \mathrm{m}$ diameter droplets. The origin of the $\mathrm{Ni}$ emission plume was located $\sim 1 \mathrm{~mm}$ below the arc channel ( $-1 \mathrm{~mm}$ vertical coordinate in Fig. 3b). Positional uncertainty in the plume origin typically was $\pm 0.5 \mathrm{~mm}$. Some rather erratic horizontal movement also was detected. This may be the result of convective turbulence from the Ar cooling gas streams and from the arc itself.

All values in Fig. 7 represent averages of four measurements along the flame axis. While the Ni line intensity along the flame axis for the $0 \mathrm{~mm}$ vertical coordinate is significantly greater

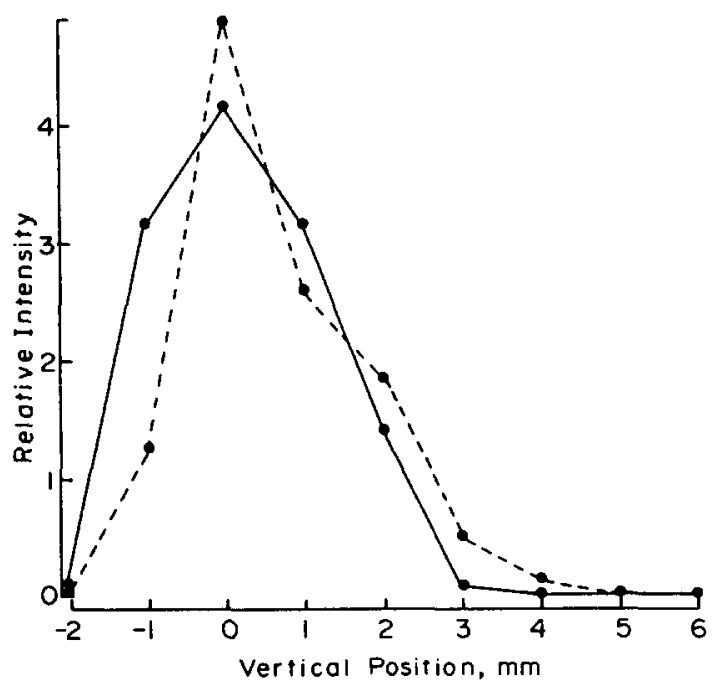

Fig. 7. $\mathrm{Ni}(\mathrm{I}) 341.4 \mathrm{~nm}$ (solıd line) and continuum background (broken line) intensities as functions of vertical position in the arc plasma tail flame. The emission plume origin was located at the $-1 \mathrm{~mm}$ vertical position just under the conduction channel. 
than for the $-1 \mathrm{~mm}$ coordinate, the nearly four-fold increase in background intensity results in a correspondingly lower line-to-background intensity ratio. Some $\mathrm{Ni}$ radiation was detected at the $-2 \mathrm{~mm}$ vertical position, and this again reflects both jitter in the vapor plume origin and convective turbulence. With increasing vertical distance in the tail flame region, both the $\mathrm{Ni}$ line intensity and the continuum background intensity decrease rapidly, but the line-to-background ratio is always less than at the $-1 \mathrm{~mm}$ vertical coordinate. It should be noted that the $-1 \mathrm{~mm}$ vertical coordinate is the usual observation zone for both the 2 electrode and 3-electrode bent arc systems.

From Fig. 7 it is not possible to determine if radiation observed in the current channel and tail flame regions results from analyte vapor in these regions or from vapor swept around the channel in the convective flow. While the thermally induced barrier may prevent vapor species or small particles from entering the channel, the relatively large particles used here moving at the moderately high convective velocity of the flame may result in some solute penetration.

The plots in Fig. 8 were obtained by decreasing the burner port-to-arc distance so that the vapor plume origin was located about $1 \mathrm{~mm}$ above the arc channel (curve A) and $2 \mathrm{~mm}$ above the channel (curve B). Again, the $\mathrm{Ni}(\mathrm{I}) 341.4 \mathrm{~nm}$ line was measured from $80 \mu \mathrm{m}$ droplets. However, because of the very large $\mathrm{Ni}$ line intensity observed with the plume origin at the $1 \mathrm{~mm}$ coordinate, the concentration was reduced to $10 \mu \mathrm{g} \mathrm{m}^{-1}$ so that the line and background intensities could be displayed on the same scale.

The increase in both line intensities and line-to-background ratios in Fig. 8 relative to Fig. 7 is dramatic. The peak line intensity with the vapor plume origin at $1 \mathrm{~mm}$ is more than an order of magnitude greater than with the origin at $-1 \mathrm{~mm}$ despite a 10 -fold decrease in concentration.

With the vapor plume origin at the $1 \mathrm{~mm}$ vertical position, the greatest $\mathrm{Ni}$ intensity also occurs at this position. However, the line-to-background ratio is greatest about $1 \mathrm{~mm}$ above the plume origin. The ratio value of $\sim 30$ at the $2-\mathrm{mm}$ vertical position is noteworthy. Greatest signal-to-noise ratio also was obtained at this vertical position.

When the vapor plume origin is raised to $2 \mathrm{~mm}$ above the conduction channel (curve $B$ ), the peak intensity occurs about $1 \mathrm{~mm}$ above the origin and is nearly a factor of 10 lower than when the origin is located $1 \mathrm{~mm}$ above the channel. The peak line-to-background ratio, which occurs at the $3 \mathrm{~mm}$ vertical position, is about a factor of 5 lower but still significantly greater than any values obtained with the vapor plume origin located in the apex region below the conduction channel.

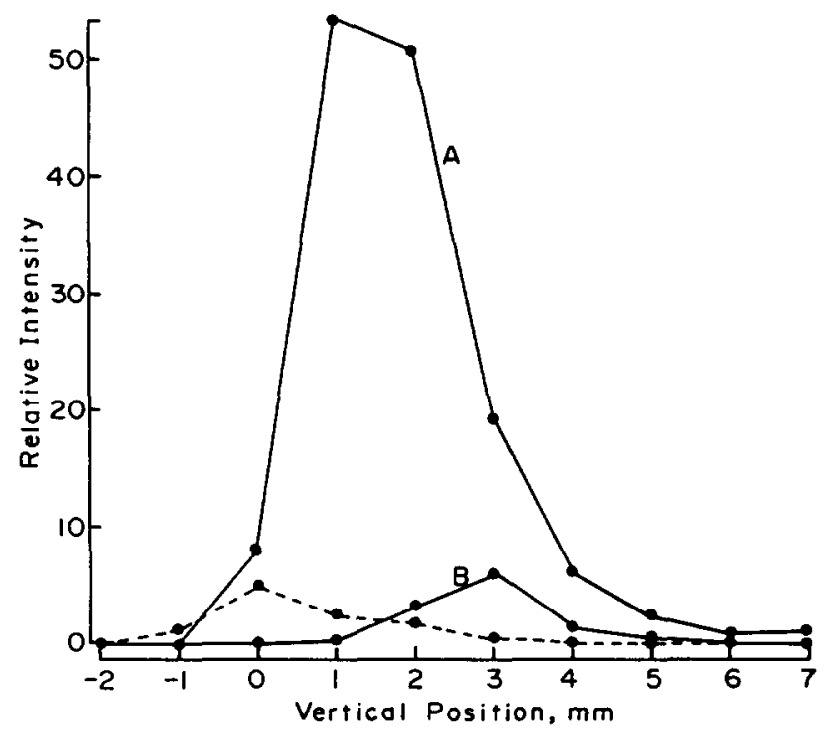

Fig. 8. Ni(I) $341.4 \mathrm{~nm}$ (solid lines) and continuum background (broken line) intensities as functions of vertical position in the are plasma tail flame. The emission plume origin was located at the $1 \mathrm{~mm}$ vertical position for curve $A$ and at the $2 \mathrm{~mm}$ vertical position for curve $B$. 
The lower line intensities observed at all vertical positions with the plume origin located $2 \mathrm{~mm}$ above the arc channel relative to values observed with the origin $1 \mathrm{~mm}$ above the channel may reflect less complete solute vaporization as well as less efficient excitation at the lower temperatures further from the channel.

\subsection{Analytical evaluation}

Analytical curves and detection limits were obtained with the analyte vapor plume origin located about $1 \mathrm{~mm}$ above the conduction channel and the observation zone located about $1 \mathrm{~mm}$ above the plume origin.

Figure 9 shows analytical curves (log-log) for the Fe(I) $372 \mathrm{~nm}$ and Ni(I) $341 \mathrm{~nm}$ lines. Each point represents the mean of four determinations. The curves are linear and with nearly unity slopes. Analyte concentrations greater than about $100 \mu \mathrm{g} \mathrm{ml}^{-1}$ often result in droplet stream instability; while for concentrations less than about $0.5 \mu \mathrm{g} \mathrm{ml}^{-1}$, the strcam is not easily positioned in the most favourable region of the arc discharge. However, the addition of $\sim 1 \mu \mathrm{g} \mathrm{ml}^{-1}$ of any species that emits strongly in the visible region greatly facilitates positioning of the vapor plume. Positional instability in the analyte emission plume resulted in poor reproducibility with relative standard deviations typically in the $\pm 20-30 \%$ range.

Detection limits were evaluated by extrapolating intensity values from $0.5 \mu \mathrm{g} \mathrm{ml}^{-1}$ solutions to a signal-to-noise ratio of 2.0. Table 3 compares detection limits from the hybrid

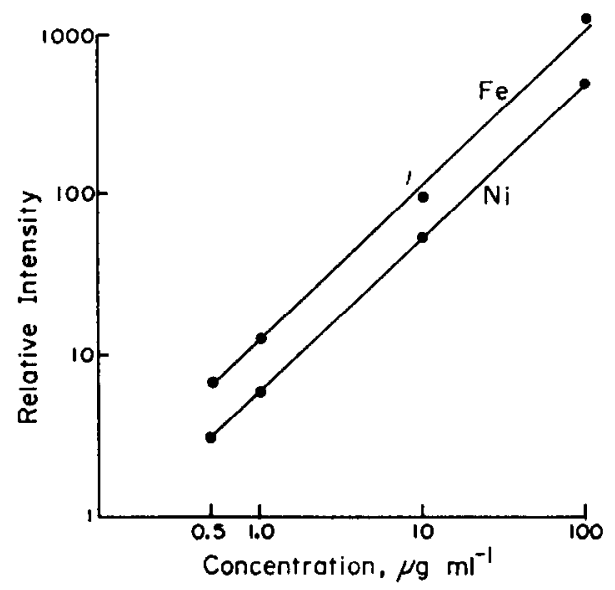

Fig. 9. Analytical curves for the $\mathrm{Fe}$ (l) 372 and Ni(I) $341 \mathrm{~nm}$ lines. The emission plume origın was located about $1 \mathrm{~mm}$ above the conduction channel, and the observation zone was located about $1 \mathrm{~mm}$ above the plume origin.

Table 3. Comparison of detection limits.

\begin{tabular}{lcccc}
\hline & & \multicolumn{3}{c}{ Detection limits $\left(\mu \mathrm{g} \mathrm{ml}^{-1}\right)$} \\
\cline { 3 - 5 } Element & $\begin{array}{c}\text { Analysis } \\
\text { line }(\mathrm{nm})\end{array}$ & Hybrid arc & $\begin{array}{c}\text { Commercial } \\
\text { bent arc }\end{array}$ & $\begin{array}{c}\text { Other gas stabihzed } \\
\text { arcs }\end{array}$ \\
\hline $\mathrm{Ag}$ & $(\mathrm{I}) 328.1$ & 0.03 & 0.05 & $1.3^{\mathrm{b}}$ \\
$\mathrm{Cu}$ & $(\mathrm{I}) 324.1$ & 0.007 & 0.02 & $0.05^{\mathrm{c}}$ \\
$\mathrm{Fe}$ & $($ I) 372.0 & 0.008 & 0.02 & $0.005^{\mathrm{d}}$ \\
$\mathrm{Mn}$ & (I) 403.1 & 0.006 & 0.02 & $0.20^{\mathrm{e}}$ \\
$\mathrm{Ni}$ & $($ I) 341.4 & 0.02 & 0.01 & $0.003^{\mathrm{d}}$ \\
$\mathrm{V}$ & (I) 318.4 & 0.09 & - & $0.05^{\mathrm{c}}$ \\
$\mathrm{Zn}$ & (I) 213.4 & 0.18 & 0.02 & $0.01^{\mathrm{d}}$ \\
\hline
\end{tabular}

See Ref. [8].

bH. Goto and I. Atsuya, Zeit. Anal. Chem. 225, 121 (1969).

c A. J. MitTeldorf and D. O. Landon, Spex Speaker VIII, March 1963.

${ }^{d}$ See Ref. [5].

e C. Matsumoto, S. Taniquchi, K. Suzusho and I. Sakaguchi, J. Spectrosc. Soc. Japan 2, 61 (1968). 
arc/flame system, a commercial 2-electrode $80^{\circ}$ bent arc with measurements made just under the conduction channel and other arc excitation sources used with nebulized solution samples. DECKER [14] recently obtained detection limits comparable to those obtained in this study using a 3-electrode bent arc with conventional sample nebulization. However, photographic detection was used with 15-min exposure times and a spectral bandwidth more than an order-of-magnitude less than in this study.

Detection limits for the hybrid system were obtained with only a 1P28 photomultiplier tube and a recorder. Attempts at using a lock-in amplifier synchronized to the droplet generator excitation frequency were unsuccessful because of phase jitter caused by positional instability in the vapor plume origin. Boss and HIEFTJE [37] discussed this problem and developed a computer-based signal averaging technique which could significantly reduce detection limits with the hybrid system.

\section{Conclusions}

While the studies reported here are preliminary, they do suggest that significant information regarding the properties of analytically useful arc plasmas and the interaction of the plasma with an aerosol sample can be obtained with the flame/arc system. The combination of aerosol desolvation and increased particle momentum seems crucial to the successful operation of the system. The role of the flame enthalpy and convective flow in stabilizing and shaping the arc plasma needs further study.

While the monodisperse aerosol generator may not be tractable for routine analysis, it may be very useful in the design of sample introduction systems for arc plasmas. In a 1977 review, KEIRS and VICKERS [38] concluded that sample introduction is the key to the future for d.c. plasma devices used for elemental analysis. There is little doubt that the convective tail flame region of the Ar-stabilized bent arc would have some analytical advantages relative to the apex region below the conduction channel if it was more accessible to analyte vapor.

The hybrid excitation source may be useful with polydisperse aerosol samples for routine analytical determinations. A larger volume, more diffuse arc plasma with smaller thermal gradients together with a larger mean droplet size and greater injection velocity may be the key for utilization of the arc tail flame.

JoHnson et al. [18] noted that as much as $5000 \mu \mathrm{g} \mathrm{ml}^{-1}$ of Li or Cs can be introduced by pneumatic nebulization in the apex region below the current channel of a commercial 3electrode bent arc with no significant change in plasma electronic excitation temperature. This implies that there is no change in the current channel electrical conductivity and supports the notion that sample aerosol produced by pneumatic nebulization is very effectively excluded from the current channel of the Ar-stabilized bent arc. It is ironic that the thermal barrier which excludes analyte species from the most analytically useful region of the plasma also results in a more ideal, temperature invariant excitation environment.

[37] C. B. Boss and G. H. HieftJE, Anal. Chem. 51, 1897 (1979).

[38] C. D. Keirs and T. J. Vickers, Appl. Spectrosc. 31, 273 (1977). 